\title{
The effect of coarse gravel on cohesive sediment entrapment in an annular flume
}

\author{
KEN GLASBERGEN ${ }^{1}$, MIKE STONE ${ }^{2}$, BOMMANNA KRISHNAPPAN ${ }^{3}$, \\ JAMIE DIXON ${ }^{4} \&$ ULDIS SILINS ${ }^{5}$ \\ 1 GeoProcess Research Associates Inc, Burlington, Ontario, Canada \\ 2 Geography and Environmental Management, University of Waterloo, Waterloo, Ontario, Canada \\ mstone@uwaterloo.ca \\ 3 Environment Canada, Burlington, Ontario, Canada \\ 4 City of Calgary, Calgary, Alberta, Canada \\ 5 Department of Renewable Resources, University of Alberta, Edmonton, Alberta, Canada
}

\begin{abstract}
While cohesive sediment generally represents a small fraction $(<0.5 \%)$ of the total sediment mass stored in gravel-bed rivers, it can strongly influence physical and biogeochemical processes in the hyporheic zone and alter aquatic habitat. This research was conducted to examine mechanisms governing the interaction of cohesive sediments with gravel beds in the Elbow River, Alberta, Canada. A series of erosion and deposition experiments with and without a gravel bed were conducted in a 5-m diameter annular flume. The critical shear stress for deposition and erosion of cohesive sediment without gravel was $0.115 \mathrm{~Pa}$ and $0.212 \mathrm{~Pa}$, respectively. In experiments with a gravel bed, cohesive sediment moved from the water column into the gravel bed via the coupling of surface and pore water flow. Once in the gravel bed, cohesive sediments were not mobilized under the maximum applied shear stresses $(1.11 \mathrm{~Pa})$ used in the experiment. The gravel bed had an entrapment coefficient (ratio between the entrapment flux and the settling flux) of 0.2. Accordingly, when flow conditions are sufficient to produce a shear stress that will mobilize the armour layer of the gravel bed $(>16 \mathrm{~Pa})$, cohesive materials trapped within the gravel bed will be entrained and transported into the Glenmore Reservoir, where sediment-associated nutrients may pose treatment challenges to the drinking water supply.
\end{abstract}

Key words erosion; cohesive sediment; entrapment; sedimentation; gravel bed

\section{INTRODUCTION}

Cohesive sediment is environmentally significant in aquatic systems because it can have a deleterious impact on biota (Ankers et al., 2003), habitat (Cobb et al., 1992) and influence the transport and fate of contaminants (Horowitz \& Elrick, 1987; Owens et al., 2005). An increasing number of laboratory and field-scale studies have advanced knowledge of cohesive sediment transport and storage mechanisms in aquatic systems (Packman et al., 2000; Rehg et al., 2005; Krishnappan \& Engel, 2006; Collins \& Walling, 2007; Krishnappan, 2007). These and other studies show that entrapment of cohesive sediment is dependent on the concentration of suspended sediment, that entrapment continues until a clogging layer is formed (Diplas, 1947), and that fine sediments remain in the bed until a critical shear stress mobilizes the gravel bed (Einstein, 1968; Rehg et al., 2005). Bed form and bed mobility also influence the entrapment of cohesive sediments (Schalchli, 1992; Rehg et al., 2005; Krishnappan \& Engel, 2006). However, some uncertainty exists regarding the magnitude of conveyance losses, the environmental significance of remobilization from temporary storage as well as the duration and magnitude of long-term storage of cohesive sediments within river channel systems (Lambert \& Walling, 1998).

In a study of water quality in the Elbow River and its potential impact on water supply for the City of Calgary, Sosiak \& Dixon (2004) reported that many of the water quality problems in the Glenmore Reservoir are directly related to land-use change and its effect on the source, quality, transport and fate of cohesive sediment in the Elbow River. Accordingly, to understand and better manage the long-term impacts of land-use change on water quality and drinking water supply, there is a need to rigorously quantify processes that influence the in-stream source, transport and fate of fine sediment in this predominantly gravel-bed river. Currently, little is known about the mass of cohesive sediment stored in coarse gravel beds of the Elbow River or in-stream processes that govern entrapment of cohesive sediment. The objectives of this study are: (1) to quantify the transport and depositional properties (critical shear stress for erosion and deposition, density, 
settling velocity) of Elbow River cohesive sediments experimentally in an annular flume with and without gravel; (2) to evaluate the processes governing entrapment of cohesive sediment in gravel beds; and (3) to quantify the entrapment ratio of gravel from the Elbow River. This study examines mechanisms governing the interaction of cohesive sediments with gravel beds in the Elbow River, Alberta, Canada, and builds upon earlier entrapment studies (Krishnappan \& Engel, 2006) to advance the entrapment ratio concept for modelling fine sediment transport.

\section{METHODS}

\section{Experimental approach}

Two sets of flume experiments (with and without gravel beds) were conducted to quantify the transport and depositional properties of cohesive sediments in the Elbow River. This approach enables the entrapment of cohesive sediment by Elbow River gravel to be rigorously quantified. The experimental conditions for erosion and deposition experiments conducted in this study are listed in Table 1.

Table 1 Description of erosion and deposition experiments in the annular flume.

\begin{tabular}{lllll}
\hline Experiment & & $\begin{array}{l}\text { Shear stress } \\
(\mathrm{Pa})\end{array}$ & $\begin{array}{l}\text { Initial concentration } \\
(\mathrm{ppm})\end{array}$ & $\begin{array}{l}\text { Consolidation period } \\
(\mathrm{h})\end{array}$ \\
\hline Deposition & (no gravel) & 0.123 & 289 & 0 \\
Deposition & (no gravel) & 0.123 & 614 & 0 \\
Deposition & (no gravel) & 0.212 & 593 & 0 \\
Erosion & (no gravel) & variable & 614 & 113 \\
Erosion & (no gravel) & variable & 614 & 39 \\
Deposition & (gravel bed) & 0.48 & 181 & 0 \\
Erosion & (gravel bed) & variable & 1.7 & 39 \\
\hline
\end{tabular}

\section{Sediment collection}

Water, gravel and cohesive sediments were collected from partially submerged gravel bars of the Elbow River during low flow conditions in autumn 2011 near the confluence of the river with the Glenmore Reservoir in the City of Calgary, Alberta. Cohesive sediment and river water were collected using an inverted cone sampler (Milburn \& Krishnappan, 2003). Approximately $750 \mathrm{~kg}$ of gravel was collected and this material was sufficient to create an 8 -cm thick gravel bed in the rotating flume. All materials were shipped to the Canadian Centre for Inland Waters (CCIW) in Burlington, Ontario. Prior to the flume experiment, the gravel was pre-washed and sieved five times using a SWECO Vibro-Energy Separator ${ }^{\circledR}$. Materials $>10 \mathrm{~mm}$ were used to create a gravel bed in the flume.

\section{Flume experiments}

The series of deposition and erosion experiments listed in Table 1 were conducted in a 5-m (ring diameter) rotating annular flume located at CCIW. The flume and experimental methods are described in detail (Krishnappan, 1993; Krishnappan \& Engel, 1994, 2004). The deposition characteristics of cohesive sediment without gravel were studied in two separate experiments by adding filtered river water and a known mass of sediment to produce fully mixed concentrations of $289 \mathrm{mg} / \mathrm{L}$ and $614 \mathrm{mg} / \mathrm{L}$ in the flume. The flume was operated at high speed for 20 minutes then the speed was lowered to a constant bed shear stress of $0.123 \mathrm{~Pa}$. The flume was operated at this level for about 5 hours. During this experiment, suspended sediment concentrations were monitored at regular time intervals. Deposition experiments were repeated under the same conditions with gravel beds. The flow characteristics and bed shear stresses in the flume during these experiments were calculated using a three dimensional hydrodynamic flow model called PHOENICS (Rosten \& Spalding, 1984). 
The erosion characteristics of cohesive sediment without gravel were determined in the first erosion experiment. A cohesive sediment layer was created by mixing river water and sediment at high speed then bringing the flume to rest. The sediment-water mixture was left undisturbed for 113 hours to allow the sediment to settle and age on the flume bed. The experiment began by increasing the speed of the flume and top cover in steps, thereby incrementally applying shear stress as a stair-case function. Suspended sediment concentration in the flume of the eroded sediment was measured as a function of time. In the second erosion experiment with a gravel bed, a cohesive sediment mixture was added while the flume ran at high speed and then sediment settled in the flume as the speed decreased slowly until it stopped. After 113 hours, the speed of the flume and top cover were increased as described above and sediment concentrations in the flume were measured as a function of time. An entrapment coefficient (defined as the ratio between the entrapment flux and the settling flux) was calculated using a fine sediment transport model developed by Krishnappan \& Engel (2006). Settling velocity of cohesive sediment was calculated using the method described by Krishnappan (2007). The mass of fine sediments stored within the gravel bed of the flume was calculated using the method of Lambert \& Walling (1988).

\section{RESULTS AND DISCUSSION}

\section{Deposition and erosion characteristics of cohesive sediment}

The depositional characteristics of cohesive sediment without gravel were studied by using the same initial suspended sediment concentrations $(614 \mathrm{mg} / \mathrm{L})$ for two different shear stress conditions $(0.212$ and $0.123 \mathrm{~Pa})$. Steady state concentrations can be expressed as a fraction of the initial sediment concentration and the critical shear stress for deposition can be extrapolated using a fitted power law relationship between the fraction deposited and bed shear stress (Milburn \& Krishnappan, 2003). The deposition experiment data are presented in Fig. 1. The fractions of cohesive sediment deposited were 0.57 and 0.94 for an applied shear stress of 0.123 and $0.212 \mathrm{~Pa}$, respectively. The critical shear stress for deposition for the Elbow River cohesive sediments was determined as $0.115 \mathrm{~Pa}$.

The critical shear stress for erosion of cohesive sediment without gravel was investigated using two consolidation periods ( 39 and $113 \mathrm{~h}$ ). Results of the experiments are presented in Fig. 2. The critical shear stress for bed erosion was $0.212 \mathrm{~Pa}$ for both the 39 and $133 \mathrm{~h}$ consolidation periods. The critical shear stress for erosion of the Elbow River sediment was approximately two times higher than the critical shear stress for deposition $(0.115 \mathrm{~Pa})$, which is consistent with results observed in other studies (Stone \& Krishnappan, 1997; Milburn \& Krishnappan, 2003).

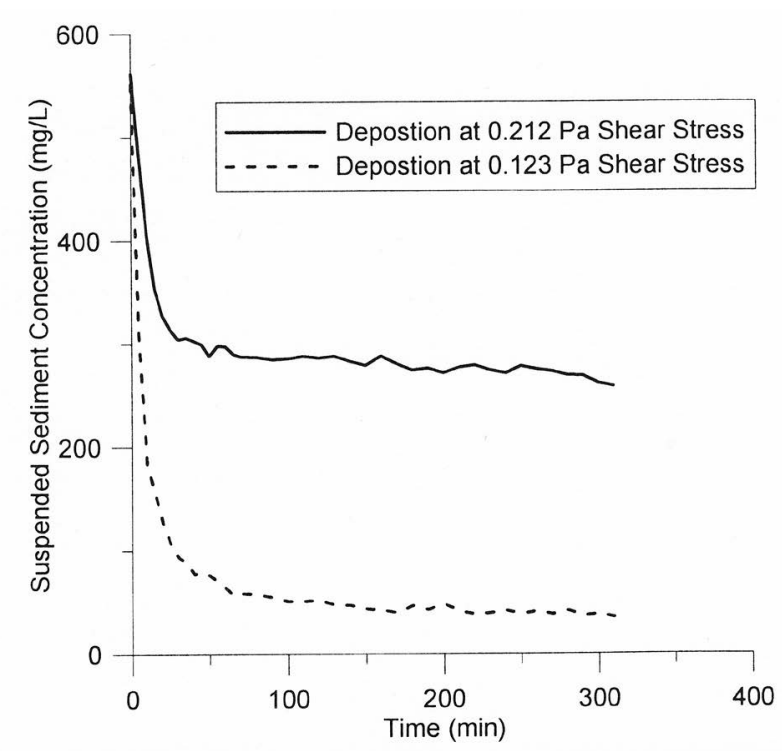

Fig. 1 Deposition of cohesive sediment for two bed shear stress conditions (0.123 Pa and 0.212 Pa). 


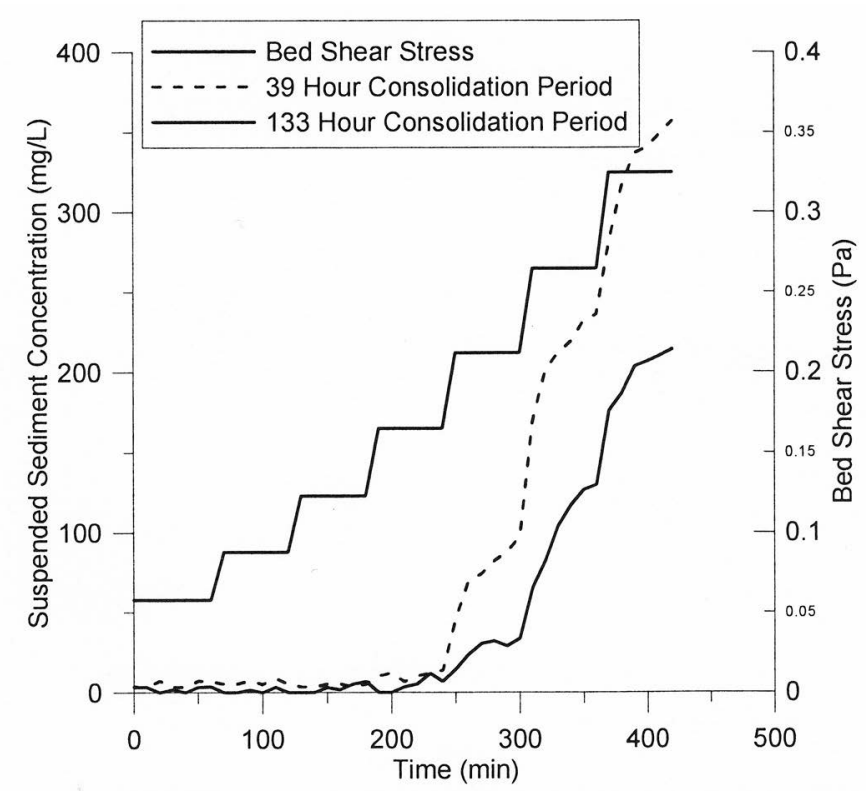

Fig. 2 Cohesive sediment bed erosion for $39 \mathrm{~h}$ and $113 \mathrm{~h}$ consolidation periods.

\section{Effect of gravel on deposition and erosion of cohesive sediment}

The results of deposition experiments in the flume with and without gravel under the same conditions of shear stress are presented in Fig. 3. During the initial 15 minutes of the experiment, suspended sediment concentrations declined rapidly to $11.9 \mathrm{mg} / \mathrm{L}$ at steady state. Figure 3 shows that $93 \%$ of the fine sediment was deposited either on or in the gravel bed compared to $56 \%$ deposited under similar flow conditions without gravel. The results are comparable to Krishnappan (2007) and demonstrate the significant effect of gravel on the deposition of cohesive sediment.

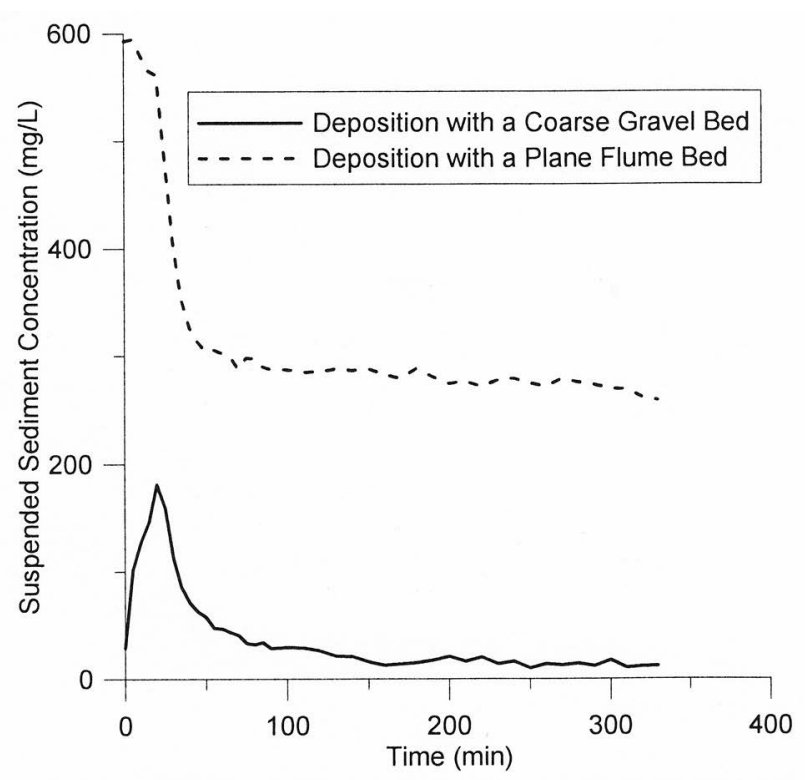

Fig. 3 Sediment deposition with and without gravel at the same flume speed.

The effect of gravel on cohesive sediment erosion was also evaluated experimentally in the annular flume. A very small fraction of the deposited sediment was remobilized under the maximum shear stresses applied in the erosion experiment with gravel (Fig. 4). Some relatively constant sediment pulsing from the gravel bed was observed was over time. The pulsing appears to have resulted from the erosion of fine sediments deposited on the top surface of the gravel bed. 


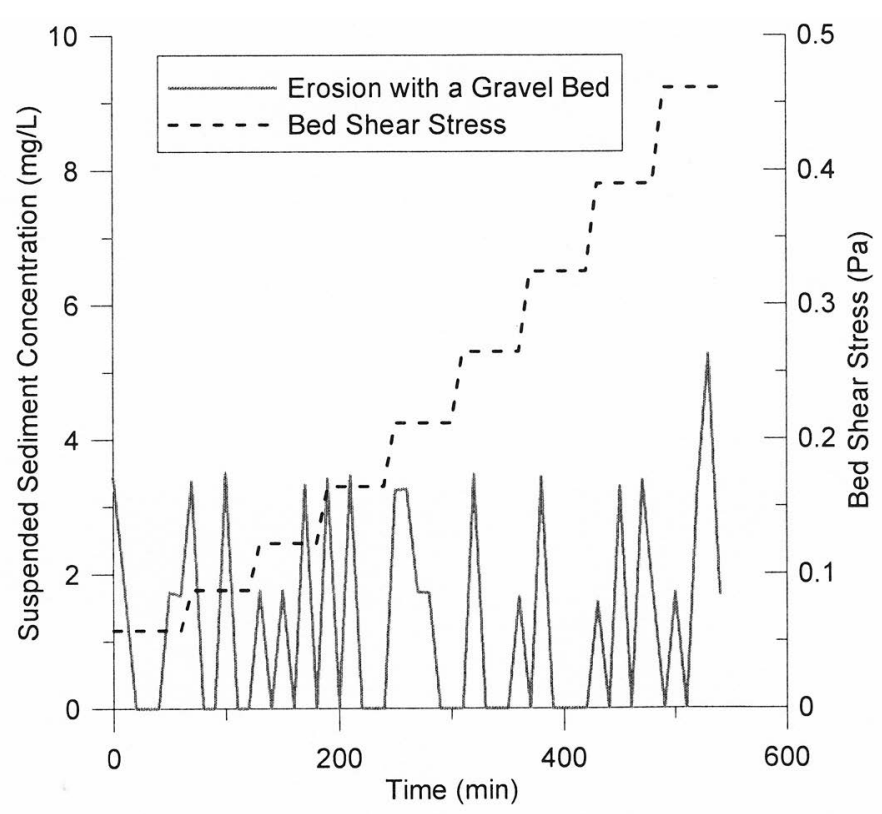

Fig. 4 Erosion experiment with coarse gravel bed.

The stochastic nature of the sediment remobilization into the water column is most likely related to the turbulent nature of flow at the boundary layer (Kirkbride \& Ferguson, 1995). It should be noted here that the concentration of the eroded sediment was very small $(<2 \mathrm{mg} / \mathrm{L})$ and is only slightly higher than the measurement accuracy of $1 \mathrm{mg} / \mathrm{L}$.

The entrapment coefficient for the Elbow River gravel was estimated to be 0.2. Krishnappan \& Engel (2006) found that the entrapment coefficient for sands varied as a function of applied shear stress. The observed difference in entrapment for the same sized sand was attributed to the stability of the bed which at low shear was stable but at a higher shear stress was mobilized. Krishnappan \& Engel (2006) observed that a mobile sand bed used in their experiments prevented a clogging layer from forming, thus resulting in a higher entrapment value than for the Elbow River gravel. The present study shows that gravel reduced the steady state sediment concentration of suspended sediment by $83 \%$ compared similar flow conditions with no gravel bed.

\section{Implications for water quality of the Glenmore reservoir}

Knowledge of cohesive sediment transport characteristics and storage/mobilization within gravel deposits of the Elbow River bed is critical to understanding its effect on water quality of the Glenmore Reservoir. The cohesive sediment fraction stored in gravel of the Elbow River was approx. $0.5 \%$ of the total sediment mass in the upper $8 \mathrm{~cm}$ of the river bed. Particle density of cohesive sediment approached that of water for size fractions $>100 \mu \mathrm{m}$. The maximum settling velocity of $50-\mu \mathrm{m}$ flocs was $0.37 \mathrm{~mm} / \mathrm{s}$ which decreased to $0.07 \mathrm{~mm} / \mathrm{s}$ for flocs of $128 \mu \mathrm{m}$ diameter (Fig. 5). Such information is relevant to the City of Calgary in the context of drinking water supply because cohesive sediment is the primary vector for phosphorus transport which can influence the trophic status of the Glenmore Reservoir (Sosiak \& Dixon, 2004). The most bioavailable particulate phosphorus forms are associated with sediment size fractions $<20 \mu \mathrm{m}$ (Stone \& English, 1993) and the phosphate desorption potential from cohesive sediment into the water column is most pronounced in the smallest size fraction (Stone \& Mudroch, 1989). Accordingly, when the armour layer of the gravel bed is mobilized during high flow events, cohesive sediment stored in the gravel will be re-entrained and transported into the reservoir. However, given the low settling velocities of the fine sediment in the water column, phosphorus desorption from the sediment into the water column will be maximized thereby increasing the potential for algal blooms. 


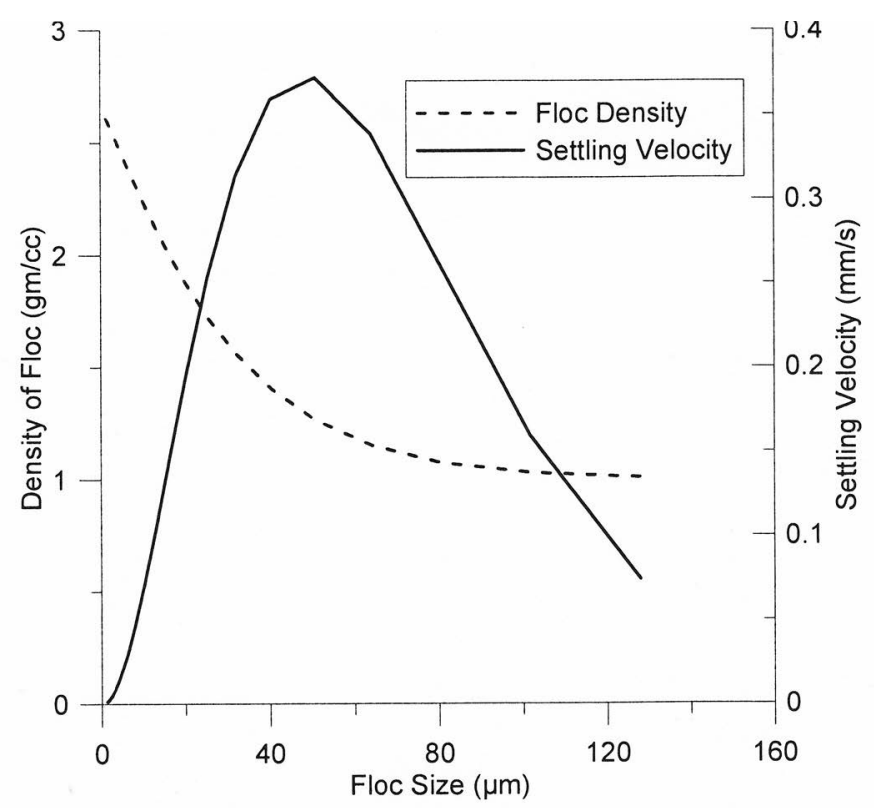

Fig. 5 Density and settling velocity of cohesive sediment.

\section{REFERENCES}

Ankers, C., Walling, D.E. \& Smith R.P. (2003) The influence of catchment characteristics on suspended sediment properties. Hydrobiologia, 494, 159-167.

Cobb, D.G., Galloway, T.D. \& Flannagan, J.F. (1992) Effects of discharge and substrate stability on density and species composition of stream insects. Canadian Journal of Fisheries and Aquatic Sciences, 49, 1788-1795.

Collins, A. \& Walling, D.E. (2007) Sources of fine sediment recovered from the channel bed of lowland groundwater-fed catchments in the UK. Geomorphology 88, 120-138.

Diplas, P. (1947) Interaction of fines with a gravel bed. Proceeding of the Federal Interagency Sedimentation Conferences.

Einstein, H.A. (1968) Deposition of suspended particles in a gravel bed. Journal Hydraulics Div. Am. Soc. Civ. Eng. 94(HY5), 1197-1205.

Horowitz, A.J. \& Elrick, K.A. (1987) The relation of stream sediment surface area, grain size and compostion to trace element chemistry. Applied GeoChemistry 2, 437-451.

Kirkbride, A.D. \& Ferguson, R. (1995) Turbulent flow structure in a gravel-bed river: Markov Chain analysis of the fluctuating velocity profile. Earth Surface Process and Landforms 20(8), 721-733.

Krishnappan, B.G. (1993) Rotating circular flume. Journal of Hydraulic Engineering, 119(6), $758-767$.

Krishnappan, B.G. (2007) Recent advances in basic and applied research in cohesive sediment transport in aquatic systems. Canadian Journal of Civil Engineering 34, 731-743.

Krishnappan, B.G. \& Engel, P. (1994) Critical shear stress for erosion and deposition of fine suspended sediments in the Fraser River. DOE FRAP 1994-13, Environment Canada.

Krishnappan, B.G. \& Engel, P. (2004) Distribution of bed shear stress in rotating circular flume. Journal of Hydraulic Engineering, 130(4), 324-331.

Krishnappan, B.G. \& Engel, P. (2006) Entrapment of fines in coarse sediment beds. River Flow 2006. Ferreira, Alves, Leal and Cardoso (eds). Taylor and Francis Group, London, 817-824.

Lambert, C.P. \& Walling, D.E. (1988) Measurement of channel storage of suspended sediment in a gravel-bed river. Catena. $15,65-80$.

Milburn, D. \& Krishnappan, B.G. (2003) Modelling erosion and deposition of cohesive sediments from Hay River, Northwest Territories, Canada. Nordic Hydrology. 34(1/2), 125-138.

Owens, P.N., et al. (2005) Fine grained sediment in river systems: Environmental significance and Management Issues, River Research and Applications 21(7), 693-717.

Packman, A.I., Brooks, N.H., \& Morgan, J.J. (2000) Kaolinite exchange between a stream and streambed: Laboratory experiments and validation of a colloid transport model. Water Resources Research 36(8), 2351-2361.

Rehg, K.J., Packman, A.I. \& Ren, J. (2005) Effects of suspended sediment characteristics and bed sediment transport on streambed clogging. Hydrological Processes, 19, 413-427.

Rosten, H.I., \& Spalding, D.B. (1984) The PHOENICS reference manual, TR/200, CHAM Ltd., Wimbleton, London.

Schalchi, U. (1992) The clogging of coarse gravel river beds by find sediment. Hydrobiologia, 235/236, 189-197.

Sosiak, A. \& Dixon, J. (2004) Impacts on water quality in the Upper Elbow River. Alberta Environment and the City of Calgary. Pub. No.:T/70 ISBN: 0-7785-3167-8.

Stone, M. \& Krishnappan, B.G. (1997) Transport characteristics of tile-drain sediments from an agricultural watershed. Water, Air and Soil Pollution 99, 8--103.

Stone, M. \& English, M. (1993) Geochemical composition, phosphorus speciation and mass transport characteristics of finegrained sediment in two Lake Erie tributaries. Hydrobiologia 253,17-29.

Stone, M. \& Mudroch, A. (1989) The effect of particle size, chemistry and mineralogy of river sediments on phosphate sorption. Environmental Technology Letters 10, 501-510. 